\title{
Relações interdisciplinares entre a Ciência da Informação e a Ciência da Comunicação: uma análise a partir de citações, formação das bancas e palavras-chave das teses das áreas ${ }^{1}$
}

João de Melo Maricato

Doutor em Ciência da Informação pela Universidade de São Paulo (USP). Pós-doutor em Ciência da Informação pela Universidade de Brasília (UNB). Professor do Programa de Pósgraduação em Ciência da Informação da Universidade de Brasília (PPGCInf/UNB).

Filipe Reis

\begin{abstract}
Mestre em Comunicação, Mídia e Cidadania pelo o Programa de Pós-graduação em Comunicação (PPGCOM) da Faculdade de Informação e Comunicação (FIC) da Universidade Federal de Goiás (UFG). Bacharel em Biblioteconomia pela FIC-UFG.
\end{abstract}

http://dx.doi.org/10.1590/1981-5344/2630

Estuda relações interdisciplinares nas e entre as áreas de Ciência da Informação e da Ciência da Comunicação, discutindo as mudanças de paradigmas que têm acontecido nessas disciplinas. Analisa as relações interdisciplinares com métodos bibliométricos e cientométricos, especificamente análises de coocorrência e cocitação. Coletou-se dados de teses de 4 programas de pós-graduação brasileiros (10 teses de cada um dos programas) e analisou-se relações entre as citações, entre a titulação da banca e entre as palavras-chave, com intuito de identificar coocorrências e, consequentemente, relações interdisciplinares nas e entre as duas áreas. Constatou-se que existem fortes relações quanto à análise de cocitação; grande variedade de formações dos membros das bancas e relativamente alta coocorrência destas entre as áreas, porém, mais intensas na área de Ciência da Informação e com mais interesse desta na área Ciência da Comunicação; não foram identificadas relações entre as duas áreas por meio da análise de coocorrência de palavras-chave. Conclui-se que ambas as áreas

\footnotetext{
${ }^{1}$ A presente pesquisa contou com o apoio da Fundação de Amparo à Pesquisa do Estado de Goiás
} 
possuem características fortemente interdisciplinares, no entanto, são mais intensas da área de Ciência da Informação do que da Ciência da Comunicação, havendo mais interesse da primeira área na segunda.

Palavras-chave: Interdisciplinaridade; Ciência da Informação; Ciência da Comunicação; Bibliometria; Cientometria.

\section{Interdisciplinary relationships between Information Science and Communication Science: analysis from citations, academic training of evaluators and keywords of these areas theses}

The paper studies interdisciplinary relations within and between areas of Information Science and Science Communication, discussing the paradigm changes that have happened in these disciplines. Analyzes interdisciplinary relationships using bibliometric and scientometric methods, specifically of co-occurrence and co-citation analysis. Data were collected for theses of 4 Brazilian graduate programs (10 theses of each program) and analyzed relations between the citations, including the area of knowledge of the evaluators and between keywords, aiming to identify co-occurences and therefore identify interdisciplinary relationships within and between the two areas. It was found that there are strong relationships as co-citations analysis; variety from the area of knowledge of the evaluators and relatively high co-occurrence between these areas, but more intense in the area of Information Science and more interest (in this area) in Communication Science area; relationships were identified between the two areas through co-occurrence analysis of keywords. We conclude that both areas have strongly interdisciplinary characteristics, however, are more intense in Information Science than the Science of Communication, with more interest the first area in the second.

Keywords: Interdisciplinarity; Information Science; Communication Science; Bibliometrics; Scientometrics. 


\section{Introdução}

A ciência nasce na Grécia, mas seu apogeu se dá a partir do século XVII com Descartes e Galileu. Desse momento adiante, a ciência e a técnica científica são consideradas os mais importantes processos de intelectualização e racionalização. As evoluções e mudanças desde o seu nascimento, para Weber, tirou o coração do cientista, ou seja, seu lado humano. Destaca-se, para o autor, o processo de especialização, o qual gerou a perda do sentido do profético e do sagrado e um grande vazio nas pessoas, bem como, a substituição da cosmovisão da tradição cultural. (WEBER, 2006).

Esse desenvolvimento da especialização da ciência, sem limites, passou a ser questionado no século $X X$, com movimentos a favor da interdisciplinaridade. Questiona-se a capacidade da ciência, excessivamente, especializada para lidar com os problemas complexos que persistiam, tais como a fome em um mundo abundante, a origem da vida, a natureza dos símbolos etc. Diante disso, a interdisciplinaridade propõe uma nova forma para constituição da ciência, que "corresponde a uma nova etapa do desenvolvimento do conhecimento científico". (JAPIASSU; MARCONDES, 2006, p. 150)

Nessa nova etapa, surgem as chamadas ciências pós Segunda Guerra Mundial, reconhecidas pelo seu caráter de relacionamento com outras ciências através do compartilhamento de conceitos, metodologias, técnicas, teorias, etc. A Ciência da Informação (CI) e a Ciência da Comunicação (CC) surgem nesse contexto, que requereu a articulação de saberes e campos para lidar com a excessiva produção da informação e com os processos comunicativos na sociedade.

Apesar de haver certa aceitação entre teóricos (MARTÍN-BARBERO, 2009; LE COADIC, 2004; PINHEIRO, 1999; SANTOS, 2012; SANTOS; RODRIGUES, 2013; SARACEVIC, 1996; SILVA, 2006) que a CI e a CC estabelecem relações interdisciplinares entre elas, e/ou com outras ciências. Compreender essas relações tem sido um desafio necessário para gerar insumos na direção de fortalecer e promover contribuições entre essas duas áreas, que têm históricas contribuições entre si.

São relativamente poucos os estudos empíricos e desenvolvimentos metodológicos que se dedicam pensar outras formas de compreensão da interdisciplinaridade, sendo uma das alternativas a construção de indicadores. Em 1992, Smith, já chamava a atenção para o fato de haver muitos trabalhos que se limitavam a enumerar áreas disciplinares, porém, sem grande desenvolvimento de estudos empíricos que demonstrassem relações interdisciplinares. Assim, propôs análises de citação com intuito de investigar interdisciplinaridades. Neste contexto, os métodos bibliométricos e cientométricos podem trazer importantes contribuições, possibilitando o estudo, medição e comparação de disciplinas e suas 
relações interdisciplinares, inclusive apresentando índices e indicadores que propiciem análises das dinâmicas e evoluções espaço-temporais.

Diante do exposto, esta empreitada científica teve como objetivo analisar relações interdisciplinares entre a CI e a CC, no Brasil, com o uso dos métodos bibliométricos e cientométricos, sobretudo baseado nas técnicas de análise de coocorrência e cocitação. Especificamente, teve como objetivo identificar relações interdisciplinares entre a CC e a CI por meio da análise da coocorrência entre as citações das duas áreas, da análise da participação em bancas dos pesquisadores nas e entre as áreas e pelo estudo concorrência temática (palavras-chave) entre elas. No entanto, faz-se necessário, para melhor compreensão desse fenômeno, discutir, a partir de um viés teórico, a interdisciplinaridade e suas características, de modo a contextualizá-la no contexto das áreas de CC e CI.

\section{Interdisciplinaridade}

A fragmentação do saber proporcionou desenvolvimento da ciência sistematicamente organizada. Contudo, apesar da especialização ser necessária, Morin (2003) afirma que esse modelo de organização da ciência pode ser arriscado, quando se torna uma hiperespecialização, ou seja, um disciplinarismo exacerbado. Tal problema foi notado, principalmente, no início do século $X X$, coincidindo com o surgimento dos primeiros movimentos em prol da interdisciplinaridade.

A história da interdisciplinaridade é marcada por lutas e movimentos entre os mais diversos atores com vistas a sua consolidação, enquanto uma nova possibilidade de organização e/ou construção do conhecimento. Tais movimentos se mostraram distantes da efemeridade, em outros termos, são ações que perduram até os dias atuais, não podendo ser considerada, portanto, uma moda passageira.

$O$ início do século $X X$ foi o crepúsculo do acentuado disciplinarismo desenvolvido, principalmente, a partir da filosofia cartesiana, que preconiza separar para melhor conhecer. A interdisciplinaridade, com uma proposta alternativa, penetrou no século XX tanto na forma participante, quanto também, como um princípio operante na produção de conhecimento.

Para Sills ${ }^{2}$ (1986), citado por Casanova (2006, p. 19), a primeira vez que palavra interdisciplinaridade apareceu foi em 1937, cunhada pelo sociólogo Louiz Wirtz. Entretanto, anteriormente, a Academia de Ciências dos Estados Unidos havia empregado a expressão "cruzamento de disciplinas" e o Instituto de Relações Humanas da Universidade de Yale havia pugnado por uma "demolição das fronteiras disciplinares".

Longe de uma visão utópica, o movimento interdisciplinar teve seu ápice na década de 1960, tempo em que o mundo vivia em efervescentes conflitos na política mundial. Estudantes protestaram e manifestaram o descontentamento com a alienação do ensino superior em relação aos

\footnotetext{
${ }^{2}$ SILLS, D. A note on the origins of interdisciplinary. Social Science Research Council, v. 40, n. 1, 1986.
} 
grandes problemas sociais. Assim sendo, Fazenda (2012) afirma que "o movimento da interdisciplinaridade surge na Europa, principalmente na França e na Itália, [...], reivindicando um novo estatuto de universidade e de escola." (FAZENDA, 2012, p. 18)

Destaca-se que esses, dentre outros marcos a favor da interdisciplinaridade, confirmaram que a delimitação unívoca de especialização acadêmica não pactuou com as necessidades do século XX. Em outras palavras, o século $X X$ solicitou novas formas de pensar a organizar a produção de conhecimento. Cabe esclarecer que o movimento da interdisciplinaridade não visa à extinção de disciplinas. Aliás, um trabalho interdisciplinar estrutura-se em disciplinas, pois é uma prática que relaciona disciplinas.

Nesse contexto, de dificuldades em relação à palavra interdisciplinaridade, surge uma família de quatro palavras que se apresentam mais ou menos equivalentes: pluridisciplinaridade, multidisciplinaridade, interdisciplinaridade e transdisciplinaridade. As fronteiras dessas palavras não estão bem estabelecidas, nem para os que a usam, nem para os que as estudam. Às vezes são usadas umas palavras, outras vezes são usadas outras. Entretanto, o mais importante não é tanto a questão nominal delas, mas sim a compressão do que se deixa pensar nessas várias palavras. Aliás, é importante notar que, apesar de gastas e banalizadas, essas palavras são recorrentes, tenazes, persistentes e constantes. (POMBO, 2005)

Apesar da complexidade e de críticas à definição e conceituação do que é interdisciplinaridade, depreende-se que a interdisciplinaridade pode ser conceituada como uma ação recíproca de relações disciplinares, tanto para a prática de aprendizagem quanto para a organização de uma classe, disciplina, matéria ou saber que visa uma um resultado qualitativo. Uma outra possibilidade de definição pode ser tomada emprestada de Japiassu e Marcondes (2006, p. 150):

Método de pesquisa e de ensino suscetível de fazer com que duas ou mais disciplinas interajam entre si, esta interação podendo ir da simples comunicação das ideias até a integração mútua dos conceitos, da epistemologia, da terminologia, da metodologia, dos procedimentos, dos dados e da organização da pesquisa.

Nesse contexto, após a Segunda Guerra Mundial emergem as ciências que não se classificam, facilmente, como disciplinares. Pombo (2003) afirma o aparecimento de três grandes novos tipos de formações disciplinares: a) ciências de fronteiras; b) interdisciplinas; e c) interciências. As interdisciplinas são novas disciplinas que surgem do cruzamento das disciplinas científicas com o campo industrial e organizacional, como por exemplo, relações internacionais e organizacionais, sociologia das organizações, psicologia industrial etc. Assim, acredita-se que a CI e a CC são exemplos dessa conversa entre campos científicos, industriais e organizacionais e que as mesmas mantêm fortes relações entre si. 


\section{Ciência da informação, comunicação e interdisciplinaridade}

Com o crescimento exponencial da produção e consumo de informação passamos da era industrial para a era da informação. Essa era informacional é marcada pelas mudanças tecnológicas, sociais e econômicas, que propiciaram o surgimento de novas ciências para compreender e solucionar problemas surgidos no século $X X$.

A CC e a CI já se fundamentam há bastante tempo. Aristóteles com estudos da retórica, que divide o processo de comunicação em três elementos básicos (o locutor, o discurso e o ouvinte), trouxe as primeiras contribuições para o campo da comunicação. Já algumas das preocupações inerentes à CI, como por exemplo, a organização e preservação da informação, já tinham sido pensadas na Antiguidade, na Biblioteca de Alexandria. Portanto, nota-se que o processo de constituição e institucionalização dessas ciências são longínquos, iniciando-se antes de surgirem como campos de estudos no século XX.

Desde então, a comunicação tem se firmado como um domínio de investigação, o termo campo é usado de forma genérica, sem muita precisão, pois tem se referido ao conjunto de atividades sob nome genérico de comunicação. Apesar das terminologias, a CC "designa um campo de estudo e/ou de reflexões teóricas e práticas sobre o desenvolvimento, intercâmbio e consequências do processo de transmissão e recepção de mensagens mediadas tecnologicamente na sociedade." (TEMER; NERY, 2009, p. 17)

A CI possui dois momentos históricos que remetem a sua constituição como campo do conhecimento. Um deles é representado pelo Belga Paul Otlet (1868-1944) e a sistematização do Tratado de Documentação, publicado em 1943. O segundo momento, pós-guerra, é marcado pela atuação do Engenheiro e pesquisador Vannevar Bush (18901974), sendo um marco a publicação de "As We May Think", em 1945.

Borko (1968), possui uma das mais conhecidas conceituações para a Ciência da Informação, para o pesquisador, uma ciência que "investiga as propriedades e comportamentos da informação, as forças que regem o fluxo de informações, e os meios de processamento de informações para melhor acessibilidade e uso." (BORKO, 1968, p. 3).

A CI, como denomina Le Coadic (2004, p. 20), é uma das novas interdiciplinas, pois a CI "traduz-se por uma colaboração entre diversas disciplinas, que leva a interações, isto é, uma certa reciprocidade nas trocas, de modo que haja, em suma, enriquecimento mútuo".

A concepção dessas duas ciências, na literatura, demonstra-se, eminentemente, interdisciplinar. Para Martino (2006), isso é percebido que a Comunicação passa a ser vista como uma ciência interdisciplinar a partir dos anos de 1980. Já na CI, a concepção de ciência interdisciplinar foi percebida desde sua conceituação com Borko, em 1968. Alguns autores defendem a existência de relações interdisciplinares entre essas duas áreas, sendo complexa a separação total entre os conceitos de 
informação. Neste sentido, Araújo (2011, p. 55) destaca que "essa relação parece confluir num sentimento misto de amor e ódio, uma vez que, sendo campos afins, há a dificuldade de diferenciá-los, o que pode acarretar, ao mesmo tempo, pontos positivos e negativos."

A literatura da Comunicação não apresenta grande recorrência de estudos que apontam relações interdisciplinares com a CI. Contudo, a CI tem um histórico de citações e argumentos que defendem que o campo da Comunicação estabelece relações próximas com a Ciência da Informação. Para Saracevic (1996), essas duas áreas compartilham um interesse na comunicação humana; compreendem a informação como fenômeno e a comunicação como processo, mas que os dois devem ser estudados em conjunto; há uma confluência de certas correntes de pesquisas nessas duas áreas; existem algumas permutas entre professores; e o potencial de cooperação na área prática profissional e dos interesses comerciais/empíricos.

As relações interdisciplinares, notadamente, passam por mutações ao longo do tempo. Na Ciência da Informação existem relações históricas, com um grande conjunto de disciplinas, havendo persistência com a com a Biblioteconomia e a Ciência da Computação. Novas articulações disciplinares surgem, como, por exemplo, com a área de Comunicação, com aproximação cada vez mais forte. As áreas de Ciência da Informação, Comunicação e Ciência da Computação podem ser caracterizadas como um "triângulo disciplinar altamente dependente da nova ordem tecnocultural, [podendo], no futuro, levar à formação de uma disciplina com características transdisciplinares, do tipo Infocomunicação." (PINHEIRO, 2005, p. 40).

Apesar de serem campos próximos, as definições dos objetos de estudo dessas disciplinas vão delinear e direcionar as pesquisas desenvolvidas. Para a consolidação de campos científicos, normalmente, utiliza-se da especialização, instituindo zonas de conforto e de poder que podem dificultar relações interdisciplinares. Reconhece-se que "todo campo, [...], é um campo de forças e um campo de lutas para conservar ou transformar esse campo de forças." (BOURDIEU, 2004, p. 22-23). Assim, cada um desses campos vai buscar aportes para manutenção do seu status quo.

Nesse contexto, de busca por consolidação dos campos da CI e da CC, questiona-se a interdisciplinaridade. Uma das principais críticas é a dificuldade de conceituação de interdisciplinaridade. Isso dificulta o trabalho dos profissionais, pois apesar de desejosos para tal prática, não encontram base teórica consistente que revele princípios metodológicos condutores. (POMBO, 2003; 2005).

A complexidade do tema pode fazer com que os atores do campo fiquem desconfortáveis à perspectiva interdisciplinar. Porém, é fato que a CI e a CC buscaram em outras áreas aportes para sua consolidação, isso significa um processo interdisciplinar de consolidação do campo, como afirmam, Smit e Tálamo (2007, p. 39) "a interdisciplinaridade pode ser 
caracterizada pela elaboração [...] de conceitos específicos da área, fertilizados por conceitos provenientes de outras áreas."

As relações interdisciplinares entre essas duas ciências são questões discutidas em algumas pesquisas, citam-se algumas para uma breve ilustração. O professor Silva (2006), em "Informação e Comunicação: as duas faces de Jano", segue uma trajetória que visa fazer uma análise etimológica e conceptual até uma indagação epistemológica exploratória do posicionamento da Ciência da Informação face às denominadas Ciências da Comunicação.

Já em 2007, Brambilla et al. refletiu sobre as tendências temáticas curriculares do campo da CI, verificando interfaces com a CC. Em 2014, Maricato e Reis analisaram as relações entre a CI e a CC, identificando que entre essas duas ciências existem relações interdisciplinares, não sendo possível afirmar se as áreas são muito ou pouco interdisciplinares ou se estão muito ou pouco atreladas, pois não existem parâmetros, medidas [...] consideradas interdisciplinares. (MARICATO; REIS, 2014, p. 8). Um exemplo de uma pesquisa realizada fora do contexto brasileiro, relacionado à presente pesquisa foi " $A$ study of interdisciplinarity in information science: using direct citation and co-authorship analysis", publicado por Huang e Chang (2011), identificando o aumento da interdisciplinaridade da área de CI ao longo do tempo.

Nesse contexto, percebe-se a necessidade de estabelecer uma "agenda comum" para esses dois campos, visto que autores têm defendido teoricamente essas relações e estudos empíricos têm demonstrado que, em maior ou menor medida, elas são efetivas. Assim, questionam quais são as ações que esses dois campos podem desenvolver em conjunto? Os estudos que fortaleçam as bases dessas ciências são caminhos promissores para uma melhor compreensão do campo da CC e da CI? Nesse contexto, buscou-se na bibliometria a análise de coocorrência e cocitação para compreender aspectos que auxiliem na compreensão da interdisciplinar mútua entre os dois campos.

\section{Metodologia}

Os tipos de análise e questões considerados importantes, nesta pesquisa, para investigar indícios de relações interdisciplinares entre as áreas de Ciência da Informação e de Ciência da Comunicação, foram:

a)Coocorrência de citações: Existe coocorrência de citações nas teses da área de Ciência da Informação e Ciência da Comunicação? Quais são os autores cocitados pelas áreas de Ciência da Informação e Ciência da Comunicação? Qual é o nível de relação entre essas áreas, a partir da análise de cocitações?

b)Coocorrência quanto à formação dos membros da banca: Existe mobilidade de pesquisadores de diferentes áreas nas bancas das áreas de Ciência da Informação e 
Ciência da Comunicação? Os pesquisadores da área de Ciência da Informação participam de bancas na área de Ciência da Comunicação e vice-versa? Em que medida essas relações podem ser identificadas?

c)Coocorrência de palavras-chave: As palavras-chave utilizadas nas teses das áreas Ciência da Informação e Ciência da Comunicação apresentam semelhanças, ou seja, existe a coocorrência de palavras-chave entre as áreas? Em que medida essas palavras-chave coocorrem entre essas áreas?

As fontes de dados da pesquisa empírica foram as teses de programas de pós-graduação em CI e CC com as maiores notas na avaliação da Capes e com as teses disponibilizadas de maneira atualizada eletronicamente. Com base nesse critério, os programas selecionados foram, em CI: Universidade Federal de Minas Gerais (UFMG) e Universidade Estadual Paulista (Unesp); em CC: Universidade Federal de Minas Gerais (UFMG) e Universidade do Vale do Rio dos Sinos (Unisinos).

Após selecionar os programas de pós-graduação das duas áreas, delimitou-se a análise das últimas dez teses depositadas nas bases das instituições de cada programa de pós-graduação escolhido. Sendo assim, foram baixadas 40 teses para análise (10 de cada programa de pósgraduação). Como existe quantidade variável de teses defendidas nos programas, a seleção possui assimetria nas datas de publicação. Assim, as últimas dez teses disponibilizadas pelos programas de pós-graduação pesquisados são do período entre 2009 e 2014 na Ciência da Comunicação e entre 2013 e 2014 na Ciência da Informação.

Foram levantados dados de autores citados na lista de referência de cada uma das 40 teses, desconsiderando-se autor entidade (associações, empresas, instituições, eventos etc.), autoria desconhecida, outros tipos de responsabilidades (tradutor, prefaciador e ilustrador) e órgão governamental. A única exceção, considerada para as análises, foi a autoria Brasil.

Em seguida, foram identificados os nomes dos pesquisadores que participaram das bancas, incluindo o(a) orientador(a) de cada uma das 40 teses. Posteriormente, foi identificada a titulação em nível de graduação, mestrado e doutorado desses na plataforma do Lattes do CNPq.

Após o levantamento das titulações em nível de graduação, mestrado e doutorado das bancas, realizaram-se pequenas padronizações de alguns termos que representavam formações aproximadas, mas eram nomeados de forma diferente.

Posteriormente, foi feito o levantamento das palavras-chave, que se apresentam junto ao resumo de cada uma das 40 teses. Salienta-se que houve pequenas padronizações dos termos com maior proximidade. A título de exemplo, cita-se o termo afro-brasileiro, que foi substituído (ou agrupado) por afrodescendente. No entanto, não foi realizado nenhum 
tipo de análise documentária ou agrupamento por algum tipo de vocabulário controlado.

Após esse processo, os dados foram padronizados, refinados, houve cruzamentos e construção de tabelas para subsidiar as análises. Os softwares utilizados foram o Microsoft Excel e o Ucinet. A Figura 1 clarifica o processo de levantamento, extração e análise dos dados para esta pesquisa.
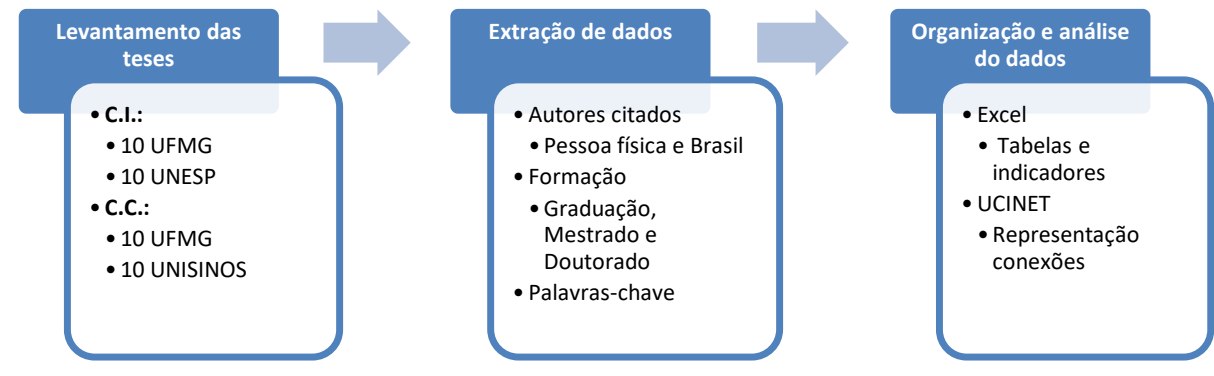

Figura 1 - Processo de levantamento, extração e análise dos dados das teses das áreas de CI e CC

Fonte: Dados da pesquisa.

\section{Resultados e discussões}

Antes de mostrar as relações entre as ciências analisadas são apresentados, brevemente, os dados que caracterizam a CI e CC individualmente.

Inicia-se, apresentando na Tabela 1 , os 20 autores mais citados na área de Ciência da Informação nas 20 teses analisadas. Observa-se que se trata de um grupo, relativamente, predominante que pode ser considerado, até certo ponto, um núcleo de autores, visto que juntos receberam $12 \%$ de todas as citações. Percebeu-se, porém, que a CI citou 1069 autores, mas, desse total, apenas 261 chegaram a ter mais de uma citação.

Tabela1 - Os 20 autores mais citados nas teses defendidas nos programas de Ciência da Informação

\begin{tabular}{l|c|c}
\hline \multicolumn{1}{c|}{ Autores mais citados e CI } & Citações & $\%$ \\
\hline \hline BRAGA, José Luiz & 26 & $1,5 \%$ \\
\hline FAUSTO NETO, Antônio & 17 & $1,0 \%$ \\
\hline FRANÇA, Vera Regina Veiga & 17 & $1,0 \%$ \\
\hline BAUMAN, Zygmunt & 15 & $0,9 \%$ \\
\hline DELEUZE, Gilles & 14 & $0,8 \%$ \\
\hline BRASIL & 12 & $0,7 \%$ \\
\hline FOUCAULT, Michel & 12 & $0,7 \%$ \\
\hline MALDONADO, Alberto Efendy & 11 & $0,6 \%$ \\
\hline
\end{tabular}




\begin{tabular}{l|c|c}
\hline FERREIRA, Jairo & 11 & $0,6 \%$ \\
\hline MARTÍN-BARBERO, Jesús & 10 & $0,6 \%$ \\
\hline DEWEY, John & 10 & $0,6 \%$ \\
\hline ECO, Umberto & 10 & $0,6 \%$ \\
\hline SODRÉ, Muniz & 10 & $0,6 \%$ \\
\hline BARTHES, Roland & 9 & $0,5 \%$ \\
\hline GUIMARÃES, César Geraldo & 9 & $0,5 \%$ \\
\hline SILVERSTONE, Roger & 9 & $0,5 \%$ \\
\hline COGO, Denise & 8 & $0,5 \%$ \\
\hline SCHERER-WARREN, Ilse & 8 & $0,5 \%$ \\
\hline Subtotal & $\mathbf{2 1 8}$ & $\mathbf{1 2 \%}$ \\
\hline Total & $\mathbf{1 7 5 1}$ & $\mathbf{1 0 0} \%$ \\
\hline
\end{tabular}

Fonte: Dados da pesquisa.

Já a Tabela 2 apresenta os 20 autores mais citados nas teses da área de CC. Percebe-se que a quantidade global de citações é menor na CC (1337) quando comparada com a CI (1751). A quantidade de citações pelo grupo dos 20 autores mais citados é parecida, mas a importância relativa desse grupo de pesquisadores na CC é mais importante que na CI. Em outras palavras, a CC concentra suas citações em um número menor de autores. A partir desses dados, constata-se que a dinâmica de produção do conhecimento dessas duas áreas é diferente e, em certa medida, já existem indícios de que a área de CI é mais interdisciplinar quando comparada com a de CC. Entretanto, a CC se assemelha com a CI, em relação ao grupo de autores com menos de duas citações. Ou seja, a maioria dos autores identificados foi citada apenas 1 vez nessas teses, de maneira semelhante que a CI, ou seja, percebeu-se que a CC citou 884 autores, mas desse total somente 189 chegaram a ter mais de uma citação.

Tabela2 - Os 20 autores mais citados nas teses da área de Ciência da Comunicação

Fonte: Dados da pesquisa.

\begin{tabular}{l|c|c}
\hline \multicolumn{1}{c|}{ Autores mais citados em CC } & Citações & $\%$ \\
\hline BRAGA, José Luiz & 21 & $1,6 \%$ \\
\hline QUÉRÉ, Louis & 18 & $1,3 \%$ \\
\hline BOURDIEU, Pierre & 17 & $1,3 \%$ \\
\hline MARTíN-BARBERO, Jesús & 14 & $1,0 \%$ \\
\hline VERÓN, Eliseo & 14 & $1,0 \%$ \\
\hline CASTELLS, Manuel & 13 & $1,0 \%$ \\
\hline COGO, Denise & 10 & $0,7 \%$ \\
\hline PERUZZO, Cićlia M Krohling & 10 & $0,7 \%$ \\
\hline BARTHES, Roland & 9 & $0,7 \%$ \\
\hline CHARAUDEAU, Patrick & 9 & $0,7 \%$ \\
\hline ESCOSTEGUY, Ana Carolina & 9 & $0,7 \%$ \\
\hline FAUSTO NETO, Antônio & 9 & $0,7 \%$ \\
\hline FRANÇA, Vera Regina Veiga & 9 & $0,7 \%$ \\
\hline GOHN, Maria da Glória & 8 & $0,6 \%$ \\
\hline LEAL, Bruno Souza & 8 & $0,6 \%$ \\
\hline MALDONADO, Alberto Efendy & 8 & $0,6 \%$ \\
\hline MORIN, Edgar & 8 & $0,6 \%$ \\
\hline SANTOS, Boaventura de Sousa & 8 & $0,6 \%$ \\
\hline Subtotal & $\mathbf{2 0 2}$ & $\mathbf{1 5} \%$ \\
\hline Total & $\mathbf{1 3 3 7}$ & $\mathbf{1 0 0} \%$ \\
\hline
\end{tabular}


Pode-se observar, com esses dados preliminares, que existem afinidades ou relações entre a CI e a CC, visto que já se pode constatar que autores citados na CI também foram citados na CC. Provavelmente, as duas áreas buscam fundamentos em fontes bastante parecidas para construir suas pesquisas. Apenas para exemplificar, destaca-se que 0 pesquisador José Luiz Braga é o pesquisador mais citado em ambas as áreas ( 26 vezes citados na CI e 21 na CC).

A fim de aprofundar o estudo das relações entre a CC e a CI, foi realizada a análise de cocitação com o Ucinet, representada, graficamente, na Figura 2. Ela ilustra, ao centro, os 198 autores que foram cocitados (citados tanto pela CC quanto pela CI) e o total de 1170 cocitações (citações recebidas por esse conjunto de autores). Salienta-se que o universo é de 884 autores e 1137 citações em CC (aglomerado à esquerda) e 1069 autores e 1751 citações em CI (aglomerado à direita). Assim, o total de autores citados pelas áreas foi de 1716 , os quais receberam o total de 3088 citações. A partir desse conjunto de dados, destaca-se que $12 \%$ dos autores foram cocitados e a quantidade de cocitações dos trabalhos desses autores corresponde a $38 \%$.

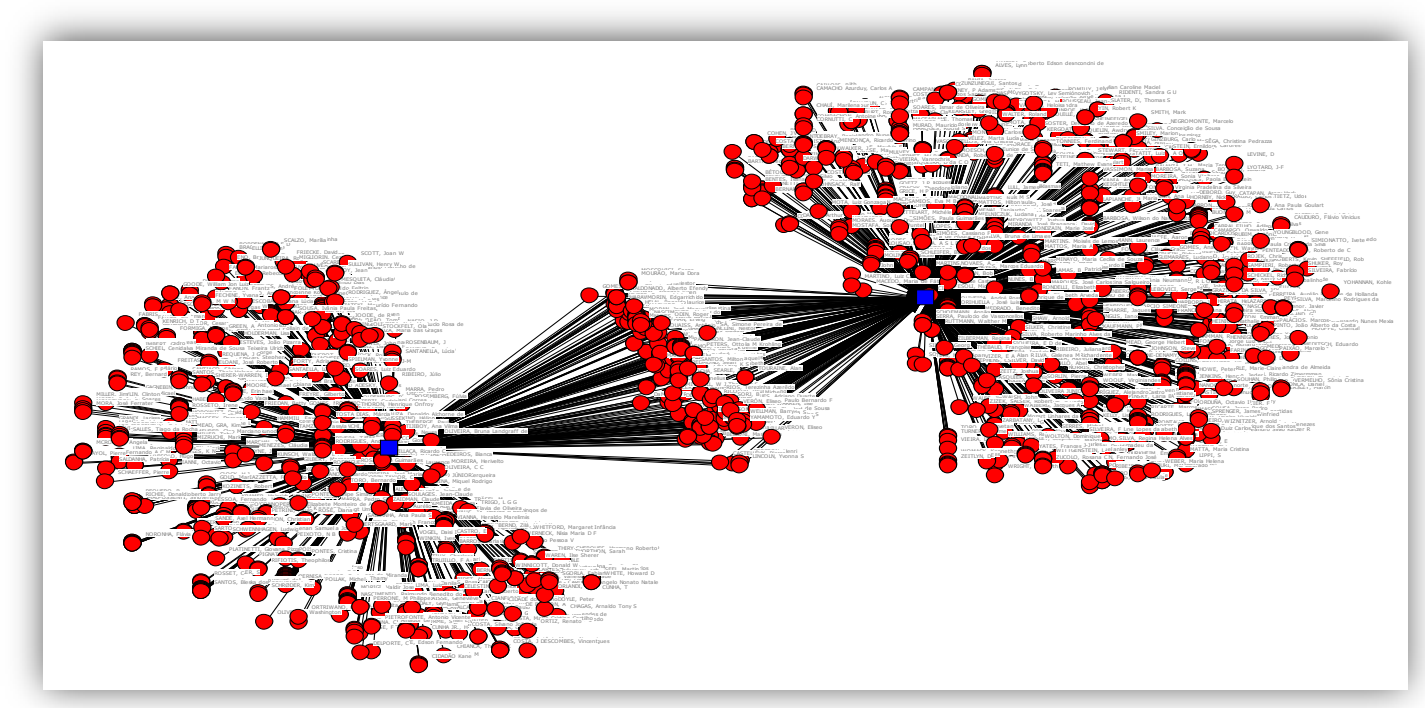

Figura 2 - Autores citados nas teses das áreas de CI (direita), nas teses de CC (esquerda) e cocitados pelas áreas (ao centro)

Fonte: Dados da pesquisa.

Esses resultados são muito expressivos, pois evidenciam que existem importantes relações, que podem ser consideradas interdisciplinaridades, entre a CI e a CC. Observa-se, também, que existem evidências de que em teses essas relações são mais perceptíveis quando comparadas com artigos científicos. Em uma pesquisa realizada com dados de citação de revistas científicas nas áreas de $\mathrm{CC}$ e $\mathrm{CI}$, Maricato e Reis (2014) identificaram uma relação entre as duas áreas de 
apenas $1 \%$ dos autores cocitados e $4 \%$ de cocitações destes. Portanto, pode-se inferir que a pesquisa apresentada em forma de artigo científico, provavelmente pela sua forte objetividade, deixa transparecer menos relação interdisciplinar do que em outros tipos de pesquisas, tais como teses e dissertações.

Os resultados parecem relevantes e indicam relações interdisciplinares interessantes entre as áreas, possibilitando melhor compreensão do fenômeno e propiciando uma melhor construção de ambas. Januário (2010, p. 162) afirma que "a relação interdisciplinar entre a CI e a CC tem sido cada vez mais estudada dentro de suas áreas de modo a, entre outros aspectos, aproximá-las através das suas particularidades e semelhanças."

Para uma melhor compreensão dessa dinâmica, apresenta-se na Tabela 3 os autores mais cocitados (mínimo de dez citações). É interessante observar que esse conjunto de 35 autores receberam $47 \%$ do total de cocitações ( $18 \%$ das citações de todo o universo). Portanto, esses dados apresentam um conjunto de autores, extremamente, relevantes para se conhecer pois são autores que favorecem o diálogo entre as áreas de CC e CI.

Destaca-se, porém, que existem assimetrias na distribuição de citações entre as áreas. Na Tabela 3, pode-se perceber, por exemplo, que os autores BRAGA, BARBERO, CASTELLS, MALDONAD e COGO têm, relativamente, uma média de citação similar entre as áreas de CC e CI. Já os autores QUÉRÉ, BOURDIEU e VERÓN apresentam uma quantidade citação acentuada para a CC. Por outro lado, os autores FAUSTO NETO e FRANÇA foram mais citados pela CI.

Tabela 3 - Lista dos autores mais cocitados (no mínimo dez citações) nas teses das áreas de $\mathrm{CI}$ e $\mathrm{CC}$ com alguns termos que remetem às temáticas de pesquisa

\begin{tabular}{|c|c|c|c|c|c|}
\hline Autor & Alguns termos da atuação & $\begin{array}{l}\text { Cit. } \\
\text { CC }\end{array}$ & $\begin{array}{c}\text { Cit. } \\
\text { Cl }\end{array}$ & $\begin{array}{l}\text { Cit. } \\
\text { Totais }\end{array}$ & $\%$ \\
\hline BRAGA, José Luiz & $\begin{array}{l}\text { Audiovisuais em Educação. Interpretação de Produtos } \\
\text { Mediáticos. Métodos de Pesquisa em Comunicação. } \\
\text { Mídias - Processos Sócio-Culturais. }\end{array}$ & 21 & 26 & 47 & $1,5 \%$ \\
\hline $\begin{array}{l}\text { FAUSTO NETO, } \\
\text { Antônio }\end{array}$ & $\begin{array}{l}\text { Biblioteconomia. Educação. Ciências Sociais. Serviço } \\
\text { Social. }\end{array}$ & 9 & 17 & 26 & $0,8 \%$ \\
\hline $\begin{array}{l}\text { FRANÇA, Vera } \\
\text { Regina Veiga }\end{array}$ & Comunicação. Imagem. Sociabilidade. & 9 & 17 & 26 & $0,8 \%$ \\
\hline QUÉRÉ, Louis & $\begin{array}{l}\text { Sociologia da ação. Questão regional. Epistemologia } \\
\text { das ciências sociais. Acontecimento. }\end{array}$ & 18 & 7 & 25 & $0,8 \%$ \\
\hline $\begin{array}{l}\text { MARTÍN-BARBERO, } \\
\text { Jesús }\end{array}$ & $\begin{array}{l}\text { Comunicação. Estudos culturais contemporâneos. } \\
\text { Antropologia. Semiologia. Filosofia colombiana. }\end{array}$ & 14 & 10 & 24 & $0,8 \%$ \\
\hline BOURDIEU, Pierre & $\begin{array}{l}\text { Educação. Cultura. Literatura. Arte. Mídia. Linguística. } \\
\text { Política. Sistema Colonial. Liberalismo. Globalização }\end{array}$ & 17 & 4 & 21 & $0,7 \%$ \\
\hline CASTELLS, Manuel & $\begin{array}{c}\text { Sociologia. Planejamento urbano. Comunicação. } \\
\text { Sociedade da informação. Capitalismo informacional. }\end{array}$ & 13 & 7 & 20 & $0,6 \%$ \\
\hline $\begin{array}{l}\text { MALDONADO, } \\
\text { Alberto Efendy }\end{array}$ & $\begin{array}{l}\text { Mercado de trabalho em comunicações e artes. } \\
\text { Comunicação Popular e Alternativa. Geopolítica da } \\
\text { Difusão Transnacional. Epistemologia. Teorias e } \\
\text { Metodologias da Recepção. }\end{array}$ & 8 & 11 & 19 & $0,6 \%$ \\
\hline BARTHES, Roland & Semiótica. Crítica literária. Filosofia. Sociologia. & 9 & 9 & 18 & $0,6 \%$ \\
\hline COGO, Denise & $\begin{array}{c}\text { Cultura. Cidadania. Tecnologias da Comunicação. } \\
\text { Estudos de recepção. }\end{array}$ & 10 & 8 & 18 & $0,6 \%$ \\
\hline
\end{tabular}




\begin{tabular}{|c|c|c|c|c|c|}
\hline VERÓN, Eliseo & $\begin{array}{l}\text { Semiótica. Sociologia. Filosofia. Antropologia social. } \\
\text { Semiose social. }\end{array}$ & 14 & 4 & 18 & $0,6 \%$ \\
\hline BAUMAN, Zygmunt & Globalização. Relações humanas. Pós-modernidade. & 1 & 15 & 16 & $0,5 \%$ \\
\hline $\begin{array}{l}\text { SCHERER-WARREN, } \\
\text { Ilse }\end{array}$ & $\begin{array}{l}\text { Movimentos sociais. Redes. Ações coletivas. Exclusão } \\
\text { e inclusão social. Direitos humanos. Multiculturalismo. }\end{array}$ & 8 & 8 & 16 & $0,5 \%$ \\
\hline DELEUZE, Gilles & História da filosofia. Conceituação. Capitalismo. & 1 & 14 & 15 & $0,5 \%$ \\
\hline BRASIL & Leis. Decretos, etc & 3 & 12 & 15 & $0,5 \%$ \\
\hline FOUCAULT, Michel & $\begin{array}{l}\text { Psicologia. Filosofia política. Filosofia da história. } \\
\text { Sociedade disciplinar. Poder. }\end{array}$ & 2 & 12 & 14 & $0,5 \%$ \\
\hline DEWEY, John & $\begin{array}{l}\text { Filosofia da educação. Epistemologia. Jornalismo. } \\
\text { Ética. }\end{array}$ & 4 & 10 & 14 & $0,5 \%$ \\
\hline $\begin{array}{l}\text { PERUZZO, Cicília M } \\
\text { Krohling }\end{array}$ & $\begin{array}{c}\text { Comunicação popular, alternativa e comunitária. } \\
\text { Movimentos sociais. }\end{array}$ & 10 & 4 & 14 & $0,5 \%$ \\
\hline ECO, Umberto & Semiologia. Filosofia. Linguística. & 3 & 10 & 13 & $0,4 \%$ \\
\hline BENJAMIN, Walter & Crítica literária. Filosofia. Sociologia. & 5 & 8 & 13 & $0,4 \%$ \\
\hline FERREIRA, Jairo & $\begin{array}{l}\text { Epistemologia. Midiatização. Dispositivos. Campo das } \\
\text { mídias e circulação. }\end{array}$ & 1 & 11 & 12 & $0,4 \%$ \\
\hline SODRÉ, Muniz & $\begin{array}{l}\text { Jornalismo. Sociologia. Literatura. Teoria da } \\
\text { Comunicação. Discurso na televisão. }\end{array}$ & 2 & 10 & 12 & $0,4 \%$ \\
\hline HALL, Stuart & $\begin{array}{c}\text { Sociologia. Teoria cultural. Hegemonia cultural. } \\
\text { Feminismo. }\end{array}$ & 4 & 8 & 12 & $0,4 \%$ \\
\hline $\begin{array}{l}\text { CARDOSO FILHO, } \\
\text { Jorge }\end{array}$ & $\begin{array}{l}\text { Teoria da comunicação. Música. Estética da } \\
\text { comunicação. História dos meios. Crítica cultural. }\end{array}$ & 4 & 7 & 11 & $0,4 \%$ \\
\hline GOFFMAN, Erving & $\begin{array}{l}\text { Sociologia. Antropologia. Identidade. Manicômios. } \\
\text { Prisões. }\end{array}$ & 4 & 7 & 11 & $0,4 \%$ \\
\hline $\begin{array}{l}\text { GUMBRECHT, Hans } \\
\text { Ulrich }\end{array}$ & Teoria literária. Comunicação. Artes. História. Filosofia. & 5 & 6 & 11 & $0,4 \%$ \\
\hline $\begin{array}{l}\text { SANTOS, Boaventura } \\
\text { de Sousa }\end{array}$ & $\begin{array}{c}\text { Globalização. Sociologia do direito. Epistemologia. } \\
\text { Democracia. Direitos Humanos. }\end{array}$ & 8 & 3 & 11 & $0,4 \%$ \\
\hline $\begin{array}{l}\text { GUIMARÃES, César } \\
\text { Geraldo }\end{array}$ & $\begin{array}{l}\text { Comunicação. Teoria da Imagem. Cinema Moderno. } \\
\text { Experiência estética. }\end{array}$ & 1 & 9 & 10 & $0,3 \%$ \\
\hline CERTEAU, Michel de & História. Psicanálise. Filosofia. Ciências sociais. & 3 & 7 & 10 & $0,3 \%$ \\
\hline BAKHTIN, Mikhail & Linguagem. Literatura. Arte. Linguística. & 5 & 5 & 10 & $0,3 \%$ \\
\hline THOMPSON, John B & Sociologia. Mídia. Ideologia. Sociedades Modernas. & 5 & 5 & 10 & $0,3 \%$ \\
\hline $\begin{array}{l}\text { RODRIGUES, Adriano } \\
\text { Duarte }\end{array}$ & $\begin{array}{l}\text { Comunicação. Cultura. Informação. Técnicas da } \\
\text { comunicação. }\end{array}$ & 6 & 4 & 10 & $0,3 \%$ \\
\hline LEAL, Bruno Souza & $\begin{array}{l}\text { Comunicação. Mídia. Jornalismo. Narrativa. } \\
\text { Homocultura. Experiência estética e televisiva. }\end{array}$ & 8 & 2 & 10 & $0,3 \%$ \\
\hline MORIN, Edgar & Epistemologia. Sociologia. Filosofia. Antropologia. & 8 & 2 & 10 & $0,3 \%$ \\
\hline $\begin{array}{l}\text { CHARAUDEAU, } \\
\text { Patrick }\end{array}$ & $\begin{array}{l}\text { Linguística. Teoria Sociolinguística. Análise do discurso. } \\
\text { Práticas midiáticas e políticas. }\end{array}$ & 9 & 1 & 10 & $0,3 \%$ \\
\hline Subtotal & & 252 & 300 & 552 & $18 \%$ \\
\hline Total & & 1337 & 1751 & 3088 & $100 \%$ \\
\hline
\end{tabular}

Fonte: Dados da pesquisa.

Evidencia-se na Tabela 3, pelos assuntos de pesquisa dos autores cocitados, que os assuntos e autores da área da CC são predominantes, em relação aos assuntos e autores da área de CI. Além disso, é nítida a busca de autores das ciências humanas e sociais, não havendo, entre os mais citados, autores das áreas de exatas ou biológicas.

A partir da Tabela 3, pode-se defender que há maior abertura da CI em relação às outras áreas, inclusive com a $\mathrm{CC}$, podendo, portanto, ser considerado um campo mais interdisciplinar (do que a CC). Isso fica ainda mais evidente quando se analisa a Figura 3, que apresenta a relação entre a CI e a CC por meio das titulações dos componentes da banca.

$\mathrm{Na}$ Figura 3, apresenta-se quadrados, que representam as teses das áreas de $\mathrm{CI}$ e $\mathrm{CC}$ e círculos que representam as titulações dos membros da banca. A área de CI está disposta à esquerda e a CC à direita. Observa-se, ao centro, as titulações que coocorrem, ou seja, as formações 
em que há mobilidade ou interação de pesquisadores entre as duas áreas, quer seja na formação do orientador ou de um dos membros das bancas.

Ressalta-se que as cinco titulações mais recorrentes na área de CI foram: Ciência da Informação (43; 24\%); Biblioteconomia (17; 10\%); Ciências da computação (16; 9\%); Sociologia (12; 7\%); e Comunicação $(13 ; 7 \%)$, podendo ser consideradas, a partir do critério adotado, as áreas com maiores relações interdisciplinares entre a CI

$\mathrm{Na} \mathrm{CC}$, as cinco titulações com maior representatividade foram: Comunicação (44; 42\%); Letras (19; 18\%); Literatura (07; 7\%) e Sociologia (6; 6\%); e Comunicação e Semiótica (5; 5\%). Constata-se, com esses dados, que a CI possui um conjunto de áreas com as quais mantém relações mais pulverizadas quando comparada com a CC. Apesar dessa constatação, os dados demonstram algumas das principais relações mantidas pelas duas áreas a partir da formação dos membros das bancas.

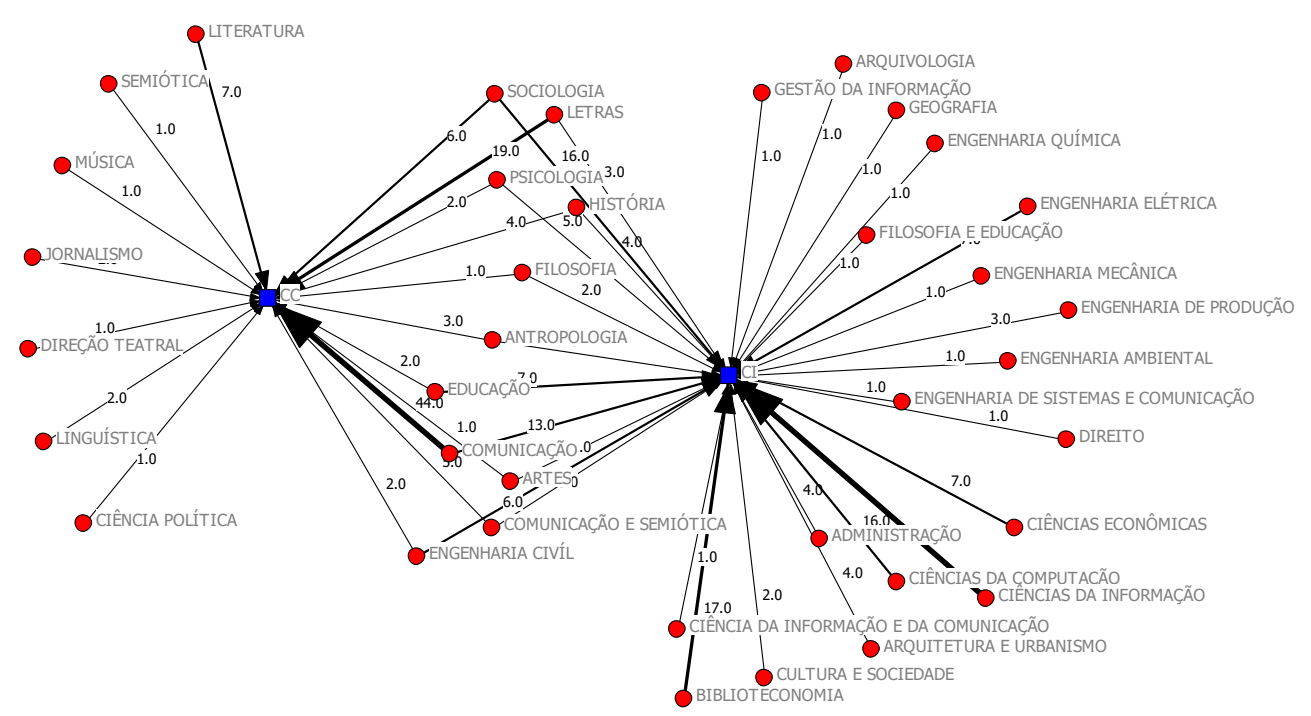

Figura 3 - Titulações dos participantes das bancas de avaliação das teses de CI (direita) e de CC (esquerda) e coocorrências (ao centro)

Fonte: Dados da pesquisa.

Constata-se, na Figura 3, uma maior abertura das bancas de CI para participantes com formações diferentes em relação às bancas da CC. Essa abertura da CI chega, inclusive, às áreas exatas com as engenharias (civil, mecânica, química, ambiental, elétrica, de produção e de sistemas e comunicação) e informática. Comportamento diferente ao da CC, que da área de exatas remeteu a apenas duas formações de membros das bancas, no caso, na área de engenharia civil.

Ao centro da Figura 3, é possível observar as coocorrências, ou pontos de confluência entre as áreas de CI e CC. Um fato interessante foi 
constatar que as bancas da CI estão abertas para participantes com formação em comunicação (13 ocorrências de formação nas bancas da área de (I), mas o contrário não aconteceu, ou seja, não houve nenhum titulado na área de CI que tenha participado de bancas da área de CC. Cabe aqui frisar que a interdisciplinaridade se diferencia pela intensidade de trocas que realizam entre especialistas, disciplinas e no interior do projeto específico de pesquisa. Sendo assim, a partir da Figura 3 é possível afirmar que a CI possui maior nível de interdisciplinaridade quando comparado com a CC. A CI, além de mostrar um interesse de certas formações para a CI, também apresenta maior interação com especialistas de outras áreas.

A Tabela 4 apresenta as áreas do conhecimento com as formações dos membros das bancas participantes das teses em CC e CI, indicando a quantidade de formações e a porcentagem para cada uma delas. Note que na Tabela 4 as linhas em destaque referem-se as áreas em que houve algum tipo de relação considerada interdisciplinar. A intensidade da relativa da importância de cada uma das áreas e entre as áreas podem ser depreendidas a partir da observação e comparação de suas porcentagens. Uma rápida análise da Tabela 4 apresenta os seguintes indicadores: a CC contou com 21 formações diferentes e a CI com 34, totalizando 44 diferentes áreas de formação nas duas áreas, sendo que 12 dessas áreas coocorrem. No entanto, a intensidade da ocorrência é mais forte na CC (85\%) quando comparado com a CI (33\%), indicando as formações das bancas da primeira é mais concentrada do que as da segunda. Mesmo assim, a intensidade média das coocorrências das formações das bancas entre as duas áreas é de $52 \%$.

Tabela 4 - Áreas de formação dos membros das bancas em CC e CC

\begin{tabular}{l|r|r|r|r|r|r}
\hline Rótulos de Linha & C & \multicolumn{1}{l|}{ CC } & Cl & \multicolumn{1}{l|}{ Cl } & \multicolumn{1}{l}{ Total } & \% Total \\
\hline \hline Comunicação & 43 & $41 \%$ & 13 & $7 \%$ & 56 & $49 \%$ \\
\hline Ciências da Informação & 0 & $0 \%$ & 43 & $24 \%$ & 43 & $24 \%$ \\
\hline Sociologia & 6 & $6 \%$ & 12 & $7 \%$ & 18 & $13 \%$ \\
\hline Biblioteconomia & 0 & $0 \%$ & 17 & $10 \%$ & 17 & $10 \%$ \\
\hline Ciências da Computação & 0 & $0 \%$ & 15 & $9 \%$ & 15 & $9 \%$ \\
\hline Letras & 10 & $10 \%$ & 2 & $1 \%$ & 12 & $11 \%$ \\
\hline Comunicação e Semiótica & 5 & $5 \%$ & 5 & $3 \%$ & 10 & $8 \%$ \\
\hline Estudos literários & 9 & $9 \%$ & 1 & $1 \%$ & 10 & $9 \%$ \\
\hline Educação & 2 & $2 \%$ & 7 & $4 \%$ & 9 & $6 \%$ \\
\hline Engenharia civil & 2 & $2 \%$ & 6 & $3 \%$ & 8 & $5 \%$ \\
\hline Ciências Econômicas & 0 & $0 \%$ & 7 & $4 \%$ & 7 & $4 \%$ \\
\hline Engenharia Elétrica & 0 & $0 \%$ & 7 & $4 \%$ & 7 & $4 \%$ \\
\hline História & 4 & $4 \%$ & 3 & $2 \%$ & 7 & $6 \%$ \\
\hline Literatura & 7 & $7 \%$ & 0 & $0 \%$ & 7 & $7 \%$ \\
\hline Psicologia & 2 & $2 \%$ & 5 & $3 \%$ & 7 & $5 \%$ \\
\hline Administração & 0 & $0 \%$ & 4 & $2 \%$ & 4 & $2 \%$ \\
\hline Antropologia & 3 & $3 \%$ & 1 & $1 \%$ & 4 & $3 \%$ \\
\hline Arquitetura e Urbanismo & 0 & $0 \%$ & 4 & $2 \%$ & 4 & $2 \%$ \\
\hline Engenharia de Produção & 0 & $0 \%$ & 3 & $2 \%$ & 3 & $2 \%$ \\
\hline Filosofia & 1 & $1 \%$ & 2 & $1 \%$ & 3 & $2 \%$ \\
\hline Sociologia & 0 & $0 \%$ & 3 & $2 \%$ & 3 & $2 \%$ \\
\hline Artes & 1 & $1 \%$ & 1 & $1 \%$ & 2 & $2 \%$ \\
\hline Cultura e Sociedade & 0 & $0 \%$ & 2 & $1 \%$ & 2 & $1 \%$ \\
\hline
\end{tabular}




\begin{tabular}{l|r|r|r|r|r|r}
\hline Jornalismo & 2 & $2 \%$ & 0 & $0 \%$ & 2 & $2 \%$ \\
\hline Arquivologia & 0 & $0 \%$ & 1 & $1 \%$ & 1 & $1 \%$ \\
\hline Ciência da Informação e da & & & & & & \\
Comunicação & 0 & $0 \%$ & 1 & $1 \%$ & 1 & $1 \%$ \\
\hline Ciência Política & 1 & $1 \%$ & 0 & $0 \%$ & 1 & $1 \%$ \\
\hline Direção Teatral & 1 & $1 \%$ & 0 & $0 \%$ & 1 & $1 \%$ \\
\hline Direito & 0 & $0 \%$ & 1 & $1 \%$ & 1 & $1 \%$ \\
\hline Engenharia Ambiental & 0 & $0 \%$ & 1 & $1 \%$ & 1 & $1 \%$ \\
\hline Engenharia de Sistemas e Comunicação & 0 & $0 \%$ & 1 & $1 \%$ & 1 & $1 \%$ \\
\hline Engenharia Mecânica & 0 & $0 \%$ & 1 & $1 \%$ & 1 & $1 \%$ \\
\hline Engenharia química & 0 & $0 \%$ & 1 & $1 \%$ & 1 & $1 \%$ \\
\hline Filosofia e Educação & 0 & $0 \%$ & 1 & $1 \%$ & 1 & $1 \%$ \\
\hline Geografia & 0 & $0 \%$ & 1 & $1 \%$ & 1 & $1 \%$ \\
\hline Gestão da Informação & 0 & $0 \%$ & 1 & $1 \%$ & 1 & $1 \%$ \\
\hline História & 0 & $0 \%$ & 1 & $1 \%$ & 1 & $1 \%$ \\
\hline Informática & 0 & $0 \%$ & 1 & $1 \%$ & 1 & $1 \%$ \\
\hline Línguas Românicas & 1 & $1 \%$ & 0 & $0 \%$ & 1 & $1 \%$ \\
\hline Linguística & 1 & $1 \%$ & 0 & $0 \%$ & 1 & $1 \%$ \\
\hline Música & 1 & $1 \%$ & 0 & $0 \%$ & 1 & $1 \%$ \\
\hline Relações Públicas & 1 & $1 \%$ & 0 & $0 \%$ & 1 & $1 \%$ \\
\hline Semiótica & 1 & $1 \%$ & 0 & $0 \%$ & 1 & $1 \%$ \\
\hline Sociologia e Política & 0 & $0 \%$ & 1 & $1 \%$ & 1 & $1 \%$ \\
\hline Total & $\mathbf{1 0 4}$ & $\mathbf{1 0 0} \%$ & $\mathbf{1 7 6}$ & $\mathbf{1 0 0} \%$ & $\mathbf{2 8 0}$ & $\mathbf{2 0 0 \%}$ \\
\hline
\end{tabular}

Fonte: Dados da pesquisa.

Essa maior abertura da CI é bem-vista aos favoráveis à interdisciplinaridade. Para Pombo (2006), essa prática interdisciplinar é o "fenômeno, não apenas torna mais articulado o conjunto dos diversos "ramos" do saber [...], como o fazem dilatar, constituindo mesmo novos espaços de investigação, surpreendentes campos de visibilidade." (POMBO, 2006, p. 210)

Japiassú (1976), o fenômeno interdisciplinar pode ser considerado como uma das manifestações mais significativas da atualidade. Partindo dessa premissa, pode-se argumentar, com base no recorte desta pesquisa, que a $\mathrm{CI}$ tem alcançado maior sucesso nessa direção quando comparado com a CC.

Com a análise das palavras-chave das teses das áreas de CI e CC, é possível inferir sobre o comportamento interdisciplinar no que diz respeito às relações temáticas entre as áreas. Constatou-se, por meio desse critério, que não existem relações entre as duas áreas quanto a ligações entre as palavras-chave, pois, nenhuma das palavras-chave da CI coincidiu com as palavras adotadas nas teses de CC.

Ressalta-se que na CC as maiores recorrências de palavras-chave foram: acontecimento; comunicação; midiatização. Mesmo assim, a recorrências dessas três palavras-chave foram dez, em um total de 101. $\mathrm{Na} \mathrm{CI}$, as palavras-chave mais citadas foram: ciência da informação; estudos de usuários; e organização e representação do conhecimento. As três palavras-chave representam sete recorrências, em um total de 97 . A partir desses dados, pode-se inferir que tanto na CI quanto na CC apresenta-se uma baixa relação quanto às palavras-chave.

No entanto, cabe salientar que, normalmente, as palavras-chave de trabalhos acadêmicos são inseridas pelos próprios pesquisadores, não 
passando por qualquer processo de análise e padronização a partir de vocabulários controlados. Acredita-se que o resultado seria diferente caso houvesse sido realizado tal processo de padronização, podendo surgir níveis de confluências.

\section{Conclusões}

Os resultados desta pesquisa não vêm esgotar o assunto, pelo contrário, eles trazem vários questionamentos. É sabido que o objeto de estudo da CI é a informação, algo que "na complexidade de categoria abstrata, é de difícil apreensão." (PINHEIRO, 1999, p. 155). Da mesma forma, entende-se que o objeto comunicação também pode ser enquadrado nessa categoria abstrata e de difícil apreensão.

Ficou evidente neste trabalho que interdisciplinaridade quebra o paradigma da ciência moderna, a qual busca incansavelmente a especialização. A interdisciplinaridade apresenta-se como possibilidade de trabalhar o conhecimento para soluções de problemas complexos da contemporaneidade. Esse pensamento fez surgir as ciências interdisciplinares. Ficou evidente que as áreas de Ciência da Informação e Ciência da Comunicação dão fortemente interdisciplinares. Cabe frisar, porém, que apesar de haver intensas e profundas relações interdisciplinares da Ciência da Informação com a Comunicação e outras disciplinas, "na fértil literatura teórica estrangeira sobre a questão há o reconhecimento do diálogo interdisciplinar, mas não de fusão de áreas". (PINHEIRO, 2000, s.p.). Portanto, não se pretende aqui defender a fusão das áreas, mas, uma reflexão sobre as possibilidades de atuação conjunta e dialógica em determinados contextos teóricos, metodológicos e conceituais, respeitando-se, porém, as especificidades e limites de cada uma das áreas. Cada área tem o seu objeto de estudo: a informação e a comunicação, respectivamente. Discutir a relação entre informação como fenômeno e comunicação como processo, pode ser considerada "valiosa porque são essas relações entre ambos que vão determinar as relações entre Comunicação e Ciência da Informação." (PINHEIRO, 1999, p. 172)

Esta pesquisa evidenciou que a CI estabelece com a CC uma relação interdisciplinar, em maior ou menor grau. Portanto, através da análise de coocorrência e cocitação identificaram-se algumas características semelhantes e relações entre elas. Destaca-se que, sobretudo, a recorrência de autores mais citados pelos dois campos, cujo percentual é relativamente alto: $12 \%$ dos autores foram cocitados e a quantidade de cocitações dos trabalhos desses autores corresponde a $38 \%$.

No entanto, as relações entre as formações entre as áreas da CI e CC ainda não são, tão intensas e a CI parece mais aberta a essa relação do que a CC. A partir das análises das formações dos membros das bancas, constata-se que a CI se apresenta mais aberta a relações interdisciplinares de uma maneira geral. Apesar da importância relativa das participações de titulados na área de CC nas bancas de CI, outras áreas, como a Ciência da Computação, possuem maior predominância. 
Apesar disto, constatou-se relações de coocorrência de $27 \%$ das áreas e intensidade das ocorrências de $52 \%$ (isso quer dizer que as áreas que coocorrem, possuem grande ocorrência quando comparadas com as demais). Portanto pode-se considerar que houve relações interdisciplinares, com maior ou menor nível de intensidade, nas áreas de Sociologia, Letras, Psicologia, História, Filosofia, Antropologia, Educação, Comunicação, Artes, Comunicação e Semiótica e Engenharia Civil.

Destaca-se, porém, o fato de que as bancas de CI contam com pesquisadores com titulação em Comunicação, mas não ocorre o contrário na CC. Questiona-se quais fatores levam esse resultado. Seriam as diferenças entre os assuntos pesquisados? Estaria relacionado com a quantidade maior de titulados na área de $\mathrm{CC}$, com relação à $\mathrm{CI}$, no Brasil, que influenciou essa dinâmica? Estaria relacionado ao maior nível de institucionalização da pesquisa na área de CC quando comparada com a CC?

Quanto à análise de coocorrência das palavras-chave entre as áreas de CI e CC observou-se a ausência de relações entre elas. Em outras palavras, entende-se que mesmo que a CI e a CC estabeleçam relações interdisciplinares, existem níveis em que cada campo vai dedicar-se para garantir seu status quo.

Entende-se que o crescimento de relações interdisciplinares pode trazer para essas duas áreas "o enriquecimento recíproco através da interação mútua, ou até mesmo do confronto de teorias e métodos." Entretanto, devido aos desafios, ressalta-se que "não se devem subestimar os obstáculos existentes para a realização da ação interdisciplinar." (SANTOS, 2013, p. 347).

Acredita-se que esta pesquisa traga subsídios para uma reflexão inicial aos pesquisadores da CI e da CC no sentido de repensarem as contribuições mútuas que essas duas disciplinas podem estabelecer para que haja um ganho mútuo, podendo construir agendas conjuntas de atividades para atender os problemas complexos da atualidade.

Apesar dessas relações interdisciplinares serem de crescente interesse por parte dos pesquisadores, as dificuldades para estabelecê-las são complexas, até mesmo pela dificuldade de definição do que é interdisciplinar. Com isso, a tentativa de investigá-la, por si só já é desafiadora, sobretudo, quando se propõem análises empíricas para tentar compreender o fenômeno. Nesse contexto, uma alternativa tem sido o uso dos métodos e técnicas bibliométricas e cientométricas, que no contexto brasileiro, ainda são utilizados de forma tímida, porém, com potencial ímpar para contribuir com a compreensão desse objeto complexo e multifacetado que é a interdisciplinaridade.

\section{Referências}

ARAÚJO, C. P. Informação, comunicação e saúde: campo interdisciplinar em construção. Informação \& Comunicação, Goiânia, v. 14, n. 1, p. 4559, jan./jul. 2011. Semestral. 
BORKO, H. Information science. What is it? American Documentation, v. 19, n. 1, p. 3-5, Jan. 1968.

BOURDIEU, P. Os usos sociais da ciência: por uma sociologia do campo científico. São Paulo: Unesp, 2004.

BRAMBILLA, S. D. S. et al. Interfaces entre os campos da comunicação e da informação. Comunicação \& Informação, v. 10, n. 2, p. 21-33, 2007.

CASANOVA, P. G. As novas ciências e as humanidades: da academia à política. Rio de Janeiro: Boitempo, 2006.

FAZENDA, I. C. Interdisciplinaridade: história, teoria e pesquisa. 11. ed. Campinas, SP: Papirus, 2012.

HUANG, M.-H.; CHANG, Y.-W. A study of interdisciplinarity in information science: using direct citation and co-authorship analysis. Journal of Information Science, v. 37, n. 4, p. 369-378, 2011.

JANUÁRIO, S. B. B. A relação interdisciplinar entre a ciência da informação e a ciência da comunicação: o estudo da informação e do conhecimento na biblioteconomia e no jornalismo. Revista Digital de Biblioteconomia e Ciência da Informação, Campinas, v. 7, n. 2, p.151-165, jan./jun. 2010.

JAPIASSU, H. Interdisciplinaridade e patologia do saber. Rio de Janeiro: Imago, 1976.

JAPIASSÚ, H.; MARCONDES, D. Dicionário básico de filosofia. Rio de Janeiro: Zahar, 2006.

LE COADIC, Y.-F. A ciência da informação. Brasília, DF: Briquet de Lemos/Livros, 1996.

MARICATO, J. de M.; REIS, F. A interdisciplinaridade entre a Ciência da Informação e a Ciência da Comunicação: uma análise de cocitações nas revistas Perspectivas em Ciência da Informação e Intercom. In: ENCONTRO BRASILEIRO DE BIBLIOMETRIA E CIENTOMETRIA, 4., 2014. Anais... Recife, PE. p. 1-8.

MARTÍN-BARBERO, J. Uma aventura epistemológica: an epistemological adventure. Matrizes, São Paulo, v. 2, n. 2, p. 143-162, 2009.

MORIN, E. A cabeça bem-feita: repensar a reforma, reformar o pensamento. 8. ed. Rio de Janeiro: Bertrand Brasil, 2003.

MARTINO, L. C. Abordagens e representação do campo comunicacional. Comunicação Mídia e Consumo, São Paulo, v. 3, n. 8, p. 33-54, nov. 2006.

PINHEIRO, L. V. R. Campo interdisciplinar da Ciência da Informação: fronteiras remotas e recentes. In: PINHEIRO, L. V. R. Ciência da Informação, Ciências Sociais e interdisciplinaridade. Brasília: IBICT, 1999. p. $155-182$.

PINHEIRO, L. V. R. Infra-estrutura da pesquisa em Ciência da Informação. DataGramaZero, Rio de Janeiro, v. 1, n. 6, dez. 2000. 
PINHEIRO, L. V. R. Processo evolutivo e tendências contemporâneas da ciência da informação. Informação \& Sociedade: Estudos, v. 15, n. 1, p. $1-22,2005$.

POMBO, O. Epistemologia da interdisciplinaridade. In: SEMINÁRIO INTERNACIONAL INTERDISCIPLINARIDADE, UNIVERSIDADE, 2003, Porto. Anais... Lisboa: 2003.

HUMANISMO,

POMBO, O. Interdisciplinaridade e integração dos saberes. Liinc em Revista, v. 1, n. 1, p. 3-15, mar. 2005.

POMBO, O. Práticas interdisciplinares. Sociologias, Porto Alegre, n. 15, p. 208-249, jan./jun. 2006.

SMITH, L. C. Intcrdisciplinarity: Approaches to understanding library and information science as an interdisciplinary field. In: VAKKARI, P.; CRONIN, B. (Ed.). Conceptions of library and information science: historical, empirical, and theoretical perspectives. London, UK: Taylor Graham Publishing, 1992. p. 253-267.

SANTOS, A. P. L. dos. Relações interdisciplinares entre a ciência da informação e a biblioteconomia: limites e possibilidades. 2012. 133f. Tese (Doutorado) - Curso de Ciência da Informação, Pós-graduação em Ciência da Informação, Universidade Federal Fluminense, Niterói, 2012.

SANTOS, A. P. L. dos; RODRIGUES, M. E. F. A interdisciplinaridade e a ciência da informação: algumas reflexões. Liinc em Revista, Rio de Janeiro, v. 9, n. 1, p. 335-349, maio 2013.

SARACEVIC, T. Ciência da Informação: origem, evolução e relações. Perspectiva em Ciência da Informação, Belo Horizonte, v. 1, n. 1, p. 4162, jan./jun. 1996.

SILVA, A. M. da. Informação e Comunicação: as duas faces de Jano. Prisma.com, v. [N.E.], n. 2, p. 3-32, 2006.

SMIT, J. W.; TÁLAMO, M. F. G. Ciência da Informação: um ciência moderna ou pós-moderna? In: LARA, M. L. G. et al. Informação e Contemporaneidade: perspectivas. Recife: Néctar, 2007. p. 27-46.

TEMER, A. C. R. P.; NERY, V. C. A. Para entender as teorias da comunicação. Uberlândia: Edufu, 2009.

WEBER, K. Ciência e política: duas vocações. São Paulo: Martin Claret, 2006. 